\title{
Clinical Application of 2D Speckle Tracking Strain for Assessing Cardio-Toxicity in Oncology
}

\author{
Laura Stefani $^{1, *}$, Gianni Pedrizzetti ${ }^{2}$ and Giorgio Galanti ${ }^{1}$ \\ 1 Clinical and Experimental Department, Sports Medicine and Exercise Center, School of Sports Medicine, \\ 50100 Florence, Italy; giorgio.galanti@unifi.it \\ 2 Department of Engineering and Architecture, University of Trieste, 34127 Trieste, Italy; giannip@dia.units.it \\ * Correspondence: laura.stefani@unifi.it; Tel.: +39-347-768-9030; Fax: +39-055-794-9902
}

Academic Editor: Giuseppe Musumeci

Received: 13 August 2016; Accepted: 20 September 2016; Published: 11 October 2016

\begin{abstract}
Echocardiography has recently undergone innovations due to the availability of deformation parameters as strain, strain rate, torsion and rotation that allow an accurate assessment of myocardial function. Because of this general progress, the importance of myocardial deformation parameters has been highlighted, and some aspects of their clinical and research applications have recently been considered for the daily management of many acute and chronic metabolic diseases. The deformation parameters are largely proposed for the early detection of myocardial dysfunction, especially in the case of patients being completely asymptomatic. Strain analysis is extensively applied to cardiomyopathies, to coronary artery disease, or to the evaluation of the "forgotten chambers", such as the right ventricles and atria. More recently, several other clinical contexts, like non-communicable chronic diseases (NCCD), have actually been benefitting from specific evaluation by strain analysis. Lately, some specific aspects of strain evaluation, particularly Global Longitudinal Strain (GLS) have been shown to provide useful information of clinical relevance in the case of cancer patients. This paper presents an initial review of the recent applications of strain analysis in cardio-oncology, in order to share the recent experience in this field and to support the role of these parameters in cardio-oncology.
\end{abstract}

Keywords: speckle tracking; myocardial function; cardio-oncology

\section{Introduction}

Strain represents a dynamic parameter for evaluating the deformation reserve from applied force, like stress, and to detect the elastic properties of the cardiac muscle [1]. In echocardiography, strain analysis is able to provide incremental information for the early clinical detection of myocardial damage in many potential myocardial failures such as asymptomatic cardiotoxicity. In particular, Speckle Tracking (ST) is a non-invasive technique recently proposed as a fundamental method to assess left ventricle (LV) function [2]. The relevance of accurate and continuous follow-up in cancer patients is widely discussed and was recently supported by stressing the importance of giving the correct indications for returning to a normal life. A complete lifestyle intervention includes several approaches, and among them, nutritional advice and physical activity are very important [3]. Cardio-oncology, and particularly Sports Medicine, work together to prevent potential myocardial failure and reduce the eventual risks of sedentarism in cancer patients. Particular attention is needed for cardiotoxicity, due to its unsuspected appearance in subjects with previous history of cancer.

Some recent clinical experiences have been extended to a pediatric context [4], where the importance of highlighting aspects of early detection of eventual myocardial dysfunction and therefore of the cardiotoxicity, has been noted in the recent literature. 
Cardiotoxicity, as an expression of LV dysfunction, is defined as a $\geq 5 \%$ reduction in symptomatic patients, or a $\geq 10 \%$ reduction in asymptomatic patients, in the left ventricular ejection fraction (EF) from baseline to a value of $<55 \%$ [5]. The incidence of cardiotoxicity has been studied in cancer patients and, among the different kinds of cancers, certain studies have been conducted mainly in breast cancer patients [6]. Authors have invested dedicated study to the increased risk of mortality from ischemic heart disease in cancer patients who were treated with adjuvant radiation or chemiotherapy [7]. The importance of a constant and correct follow-up to the myocardial function has been therefore progressively highlighted in clinical cardiology practice.

LV EF is a traditional echocardiographic parameter largely used to monitor myocardial function. However, it was recently suggested that evaluation of LV function based on this single parameter was not sufficient to detect subtle myocardial injury, especially in the case of asymptomatic patients where the history of potential heart damage can be hypothesized [8]. The literature has suggested that an integration of EF with deformation parameters represents a more accurate method for assessing heart function, especially in those cases associated with a low (less than 5\%) reduction of EF [9].

The necessity to estimate myocardial deformation is of high relevance for cancer patients where the eventual cardiotoxicity can be reversible and therefore it needs to be discovered early. This is particularly relevant because multiple morbidities can be associated with one another during cancer disease and because the eventual minimal reduction of EF cannot be recognized with confidence [10].

From the physiological point of view, the consideration that deformation imaging may provide useful information in cardio-oncology is supported by the knowledge that the final part of ejection of the left ventricle occurs by inertial effects. Therefore, the peak systolic strain rate represents an early systolic event that is more closely related to contractility than the EF [11]. Moving forward from this perspective, strain can actually represent an important instrumental approach for the deeper evaluation of myocardial function in asymptomatic patients, especially in those with almost preserved EF [12].

Myocardial deformation imaging analysis started in the late nineties using tissue Doppler imaging (TDI) [13]. A few years later, techniques of speckle tracking started to be developed for echocardiography [14-16]. ST is a method of post-processing a 2D echocardiographic image with no-angle dependence. For this reason, the recent myocardial deformation imaging investigation is preferably performed by this method, despite it being partially sensitive and limited to a high quality of image acquisition.

Numerous clinical applications of the ST strain imaging were recently presented in parallel to a progressive improvement of dedicated software tools. Among the many strain-based parameters, Global Longitudinal Strain (GLS) has been demonstrated to be the most direct, validated and reproducible for the correct assessment of the LV function [2]. Measurements of GLS were also confirmed to be reproducible enough in a comparison between different vendors software with no substantial differences [17]. These aspects supported the hypothesis that GLS is actually a "strong parameter" in echo clinical practice with different pathological applications.

The literature has recently proposed the common use of the GLS parameter in a large clinical context including several different diseases. Its use is therefore not restricted to the coronary artery disease but can be extended to the arterial hypertension [18], the valve's replacement follow-up [19], post-transplant renal recipients [20], cardiotoxicity after chemotherapy and also hypertrophic cardiomyopathies, where the distinction of the physiological from the pathological disease could be difficult.

Strain analysis is not, however, limited to GLS: circumferential and radial strain also demonstrated potential relevance in clinical applications. For example, circumferential strain can contribute to improving the knowledge of the damage in young patients with metabolic syndrome [21] as well as in hypertension [22]. However, not enough data is yet available about the potential applications in cancer patients. The recent clinical studies in this context are essentially limited to the use of GLS.

Some other radiological methods can be evocated in the follow-up of cardiotoxicity induced by cancer treatment. Among them, the Magnetic Resonance Imaging (MRI), Single Photon 
Emission Computed Tomography (SPECT), positron emission tomography (PET) and computer tomography (CT) are involved. Researchers have summarized the role of nuclear imaging techniques in the non-invasive detection of myocardial damage related to antineoplastic therapy at the reversible stage [23].

The literature reports that the Cardiac MRI is a well recognized imaging technique to screen chemotherapy-related cardiomyopathy [24]. It provides reproducible and noninvasively assessment of LV volume, mass and function. However, its high cost and low availability limit clinical routine use.

The comparison of Echo assessment with MRI or other methods supports the role of the non-invasive method in the general clinical follow-up. At the same time, the results support the high reproducibility of the data. The SPECT analysis has been proposed especially for the long term follow-up in breast cancer patients treated with taxani. It is a specific method to detect taxane-induced cardiotoxicity mainly after doxorubicin chemotherapy and a higher rate of LV dysfunction development in patients with decreased uptake, but with normal left ventricle ejection fraction at echocardiography [25]. Positron emission tomography (PET) is the gold standard technique to assess myocardial metabolism and perfusion due to its high spatial and temporal resolution and high diagnostic sensibility and accuracy. In the cardio-oncologic field, PET is useful for the diagnosis of metastatic lesions and assessment of the response to chemotherapy. However, its role in the early detection of the myocardial dysfunction is actually debated [26]. Echocardiography maintains now the principal role in the first non-invasive approach considering the cost/effective ratio.

\section{Technical Considerations for Strain Analysis}

The correct image acquisition for the longitudinal strain is normally performed from the apical $2 \mathrm{C}$, $3 \mathrm{C}$ and $4 \mathrm{C}$ views; with the eventual global value computed by their average. For a correct acquisition at rest condition, it is also important to adjust frame rate $>40 \mathrm{fps}$ or to modify up to $100 \mathrm{fps}$ in case of exercise. The measures need to be repeated at least 3-4 time for reliable results. The normal value of systolic longitudinal strain ranges around $-20 \%$ corresponding to the shortening of wall length of at least $10 \mathrm{~mm}$, in large part represented by the upward excursion of the mitral valvular plane. As an example, some figures regarding the post processing analysis from two different software packages (ESAOTE, Genova, Italy; and Philips, Andover, MA, USA) have been shown (Figures 1-4).

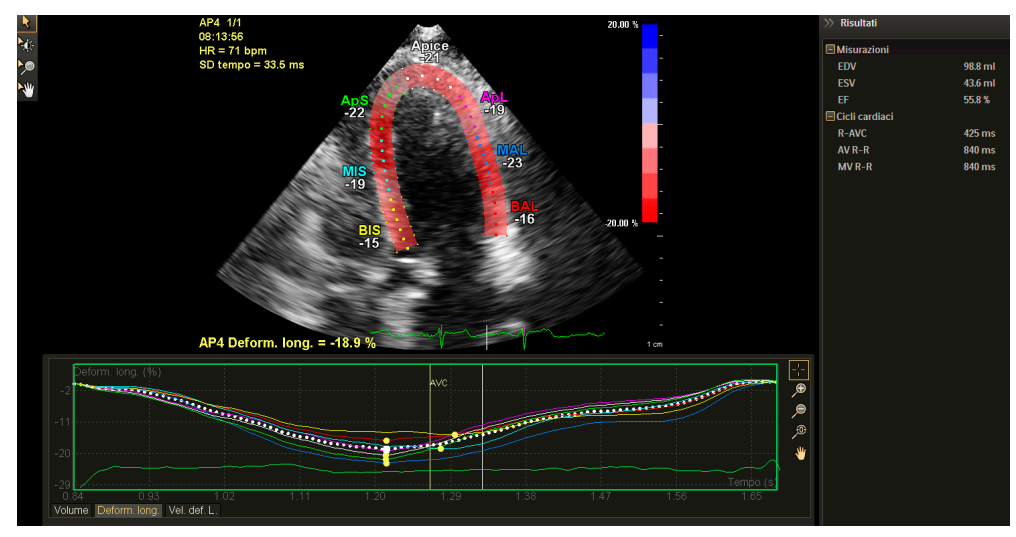

Figure 1. Global Longitudinal Strain (GLS) of left ventricle (LV) (from a four-chamber view) in a breast cancer patient under chemotherapy and treated by exercise as prescription therapy at moderate intensity. The values have been calculated by the using the iE33Philips echocardiographydedicated Strain (5X-1/Strain) software from the apex view. The figure shows the mean (dotted line) and the segmental values of the profile of the longitudinal strain analysis. The strain values have been obtained by the post processing analysis performed by X-Strain software (Q-station) included in the Philips echocardiography. The EF (ejection fraction) value (55\%) is at the lower level of the normal range and in agreement with the data of longitudinal strain $(-18.9 \%)$ data. With respect to the AVC (Aortic valve closure) marker there is evidence of a PSP (Post Systolic Peck) value. 


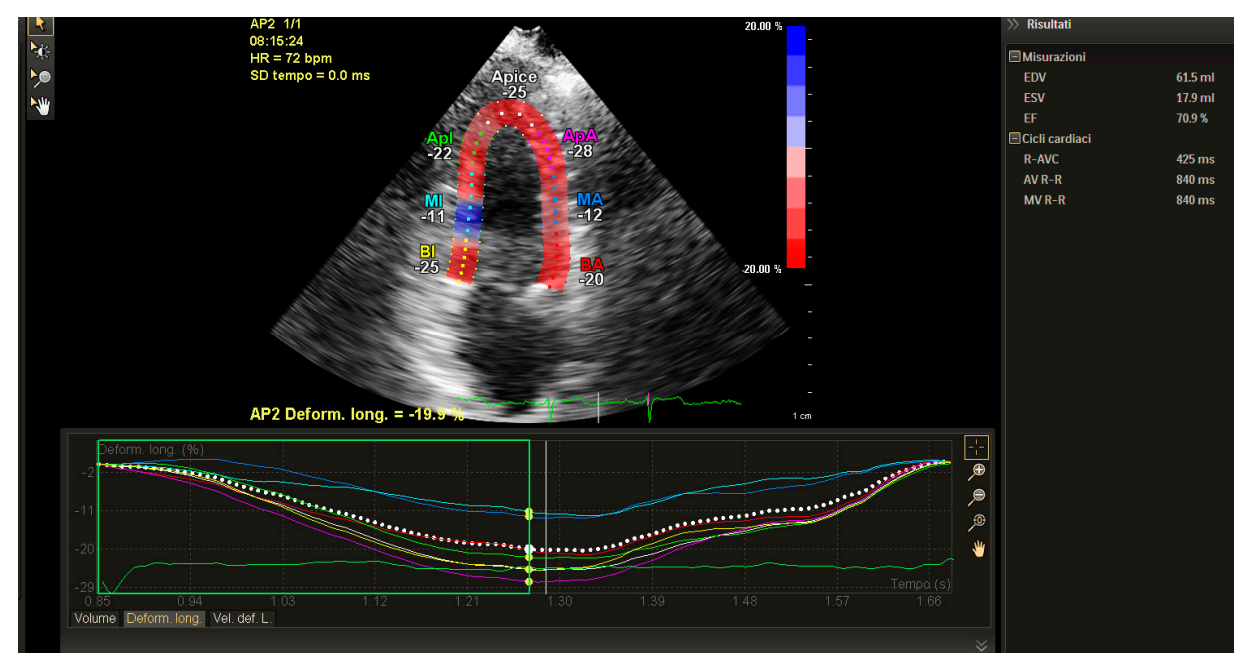

Figure 2. GLS of LV in breast cancer patient. Two-chamber view. The image shows the strain values obtained by the post processing analysis performed by Q-station, after 5X-1Strain software image acquisition. The software is included in the iE33 Philips echocardiography. The acquisition has been made from a two-chamber view. The global and segmental values are within the normal and validated range despite being at the lower limits.

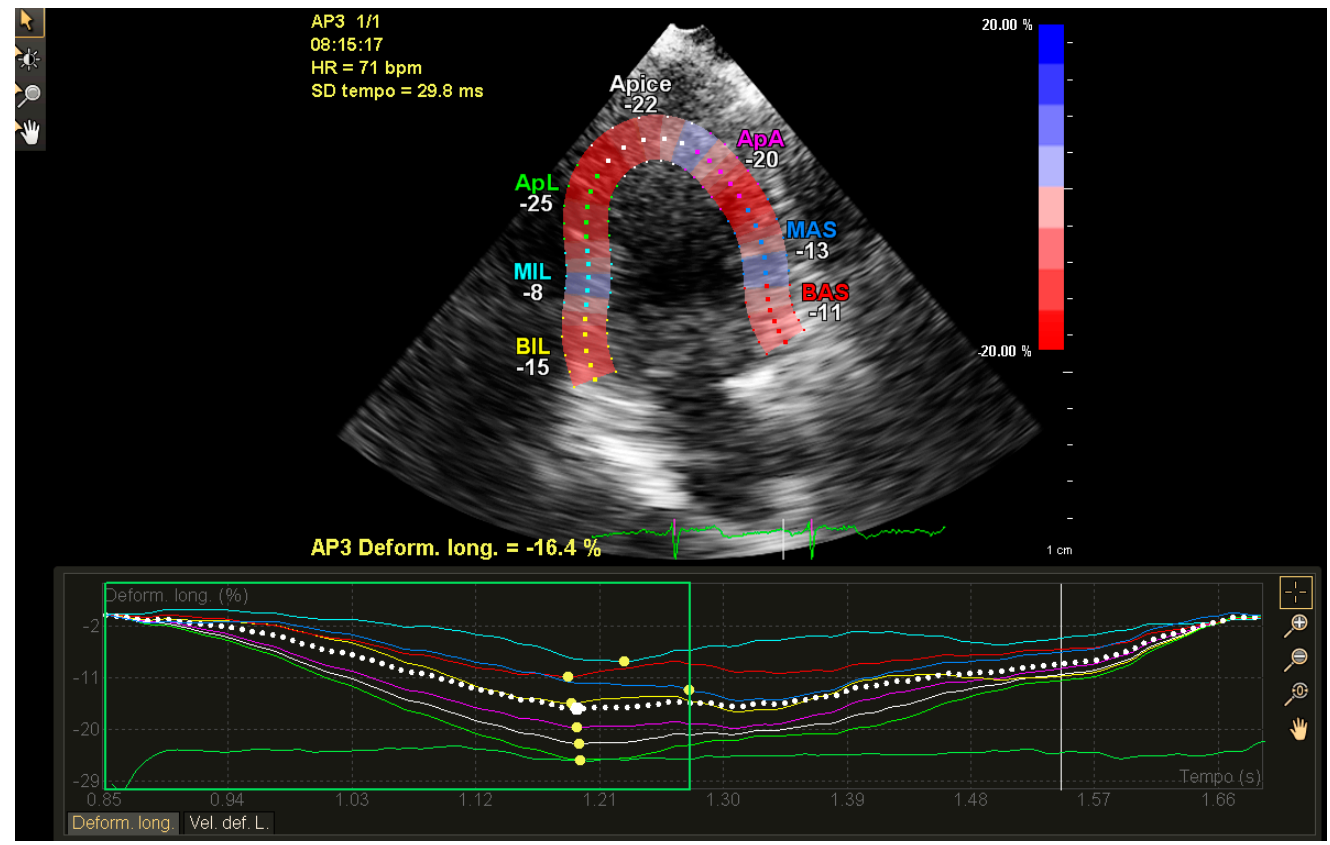

Figure 3. GLS of LV in breast cancer patient from obtained from a three-chamber view. The post processing analysis has been performed by Q-station, after $5 X-1$ Strain software image acquisition and included in the iE33 Philips echocardiography. The quality of the image is lower than that obtained in the same patient. This is one of the limits of the application The GLS values are in agreement with the values obtained in the other image analysis. In addition, the image shows a delay of strain peak values obtained potentially in accordance with the PSP (Post Systolic Peak) found in the four-chamber view. 


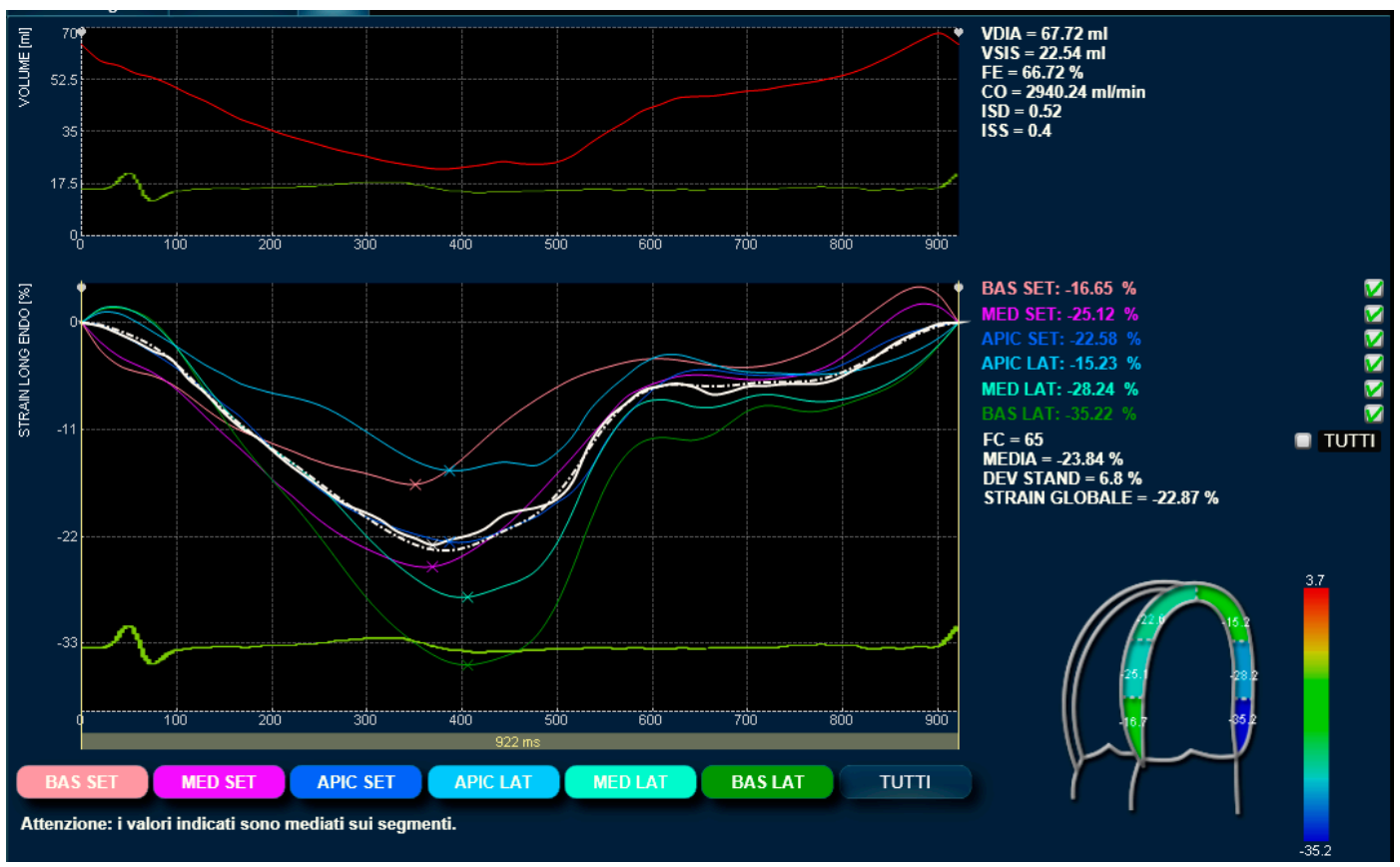

Figure 4. LV Strain analysis by X-Strain (ESAOTE-My Lab Seven) in an athlete previously affected by breast cancer and practicing Dragon Boat sport activity. The image reproduces the systolic strain profile of the segmental and global strain values of a breast cancer patient who has regularly trained. The values are all homogenously within the normal range as well in accordance to the EF.

In one case, it is particularly important to underline the potential limits due to the image acquisition, to which one is often blinded by the chest conformations. The quality of the image in Figure 3 is lower compared to the other image obtained in the same patient and with the same software. This is one of the potential limits of the clinical applications of this method; however, normally this can be overcome by multiple image acquisition for each patient.

The most used single values of strain are the peak value (minimum) or the value at end systole (ES), which do not necessarily coincide, especially in pathologic conditions. End-systolic strain also depends on the specific definition of the ES instant. In the evaluation of EF, the ES is normally defined as the instant of minimum LV volume. This represents the natural definition of the ES for the "mechanical" cardiac function; this also allows us to compute strain consistently with EF and to move beyond it.

However, in the presence of some diseases, strain permits us to distinguish between different phases of myocardial contractility, which reflect the active components of myocytes contractility associated with stress/strain ratio more than chamber loading. Different components of myocardial contraction may occur just before or immediately after the peak of the systolic phase. In those cases, it can be important to consider the aortic valve closure time (AVC) as an ES time-marker for the calculation of systolic strain components like Systolic Strain, Peak Systolic Strain, Post Peak Systolic Strain. These aspects have to be considered for a correct clinical interpretation of the systolic function, mainly in the case of the potential presence of post-systolic strain as a maker of LV dysfunction as is often found in coronary artery disease.

Strain analysis was employed in the presence of diastolic function where it appeared to be helpful to detect possible early diastolic dysfunction $[27,28]$. This aspect can have an important implication in the assessment of the heart's dysfunction and it will need some specific attention in many clinical conditions.

All these situations are particularly important in the case of cancer patients who come back to a normal life and are submitted to regular physical activity, generally prescribed because the positive 
impact maintains the myocardial performance and increases V02Max. This last parameter is strongly correlated with reduced mortality [29].

Looking in detail at GLS, the normal and validated values are within the range of $-23 \%$ to $-19 \%$, as reported in the literature [30]. GLS values were found to be an independent predictor of mortality, especially if compared to the LV EF [31]. This aspect highlights the importance to use both Strain and EF in clinical evaluation of patients where the early detection of LV dysfunction is important [32]. GLS has therefore been recently acquired in the Echo guidelines for the assessment of the systo-diastolic dysfunction and where its complementary role in addition to EF has been well underlined [33].

In parallel to strain, Strain Rate (SR), that is the rate of deformation, has also been highlighted as a useful echocardiographic parameter. SR contains intrinsic information on the contraction during different phases of cardiac cycle. However, its measurement presents a lower accuracy and large variability; therefore, results are not conclusive and for this reason it is less used in the literature [34,35].

\section{Clinical Applications of Strain for the Early Clinical Detection of Myocardial Damage}

Recent literature has explored the utility of deformation imaging for the diagnosis and prognosis of patients receiving potentially cardio-toxic cancer therapy. To date, studies have involved relatively small trials in the research setting. In contrast, strain measurement appears to be a sensitive indicator of sub-clinical diseases where many metabolic chronic diseases or patho-physiological conditions are included, and where the traditional echo parameters cannot permit us to clarify the eventual clinical diagnosis.

In numerous conditions of "suspected cardiomyopathies", the distinction between physiological and pathological conditions is crucial to stratify the cardiovascular risk. These include diabetes, systemic sclerosis, renal failure, myocardial ischemia, arterial hypertension, isolated mitral regurgitation, aortic regurgitation and all those non-ischemic cardiomyopaties, where the correct evaluation of the myocardial revascularization efficiency and the prediction of the patient's outcome with heart failure, are fundamental $[6,36]$. All these diseases are frequent in cancer patients, also as a consequence of the fact that cancer commonly occurs at ages above 55 years old when many comorbidities are often present in cancer as well as in the general population. Considering the strong attention of echocardiography in the potential clinical application of strain especially in the "grey zone" of the assessment of the physiological or pathological cardiomyopathies, cardio-oncology represents an important field for the application of strain analysis.

It is also important to consider that the incidence of cardiotoxicity for chemotherapy treatment is high. Almost $20 \%-30 \%$ of cancer patients can develop asymptomatic LV dysfunction and around $3 \%-5 \%$ show a symptomatic heart failure [37]. The high risk and the frequency of comorbidities can create an effective obstacle for a long term and correct treatment of the cancer disease. The coexistence of non-communicable chronic diseases (NCCD) are in fact the most important cause of complications in cancer patients, with a significant augmentation of mortality. A deep and more extensive noninvasive approach for an adequate follow up seems to be mandatory. A brief clinical summary of the potential application of this method in survivors of breast cancer who were previously submitted to a chemotherapy treatment, but actually completely free of the disease and are currently practicing sport activity, shows as the deformation parameters and particularly GLS is very helpful in the sports medicine follow-up [38].

All the strain values are within the normal range, despite being significantly lower if compared to the control group (Table 1). 
Table 1. Comparison of GLS value of female athletes: a group of survivors of breast cancer practicing Dragon Boat sport vs. a group of healthy athletes from different kinds of sports [39].

\begin{tabular}{ccccccc}
\hline Subjects & Strain Glob & Strain Lo Med & Strain Bas Sept & Strain Bas Lat & Strain Apex Lat & Strain Apex Set \\
\hline DB: 35 & $-21.22 \pm 5.3$ & $-19.01 \pm 5.05$ & $-16.35 \pm 5.3$ & $-18.26 \pm 7.9$ & $-18.93 \pm 5.8$ & $-24.42 \pm 5.3$ \\
Ctr: 20 & $-25.43 \pm 2.1$ & $-24.1 \pm 2.1$ & $-23.50 \pm 4$ & $-25.08 \pm 4.1$ & $-23.08 \pm 0.5$ & $-25.94 \pm 4$ \\
$p$ & 0.02 & 0.008 & 0.002 & 0.03 & 0.02 & NS \\
\hline
\end{tabular}

DB: Dragon Boat group; Ctr: control group; NS: Not Significant.

\section{Strain in Cardio-Oncology}

Many clinical trials support the role of myocardial strain in oncology, just a brief review of the principal manuscripts (simply searching in MEDLINE keywords like "deformation parameters", "cancer", "echocardiography", "cardiac toxicity", and their variations as key words) in the last decades shows the growing interest that this field is developing. It emerges from the literature that deformation imaging, strain and particularly the role of GLS is being incrementally used in this field. Recently, GLS was proposed as an appropriate tool in cardio-oncology to follow patients in a post chemotherapy treatment to detect the development of myocardial dysfunction early [40]. In fact, recent literature suggests the use of both left ventricle EF and the evaluation of LV myocardial deformation by GLS, in addition to troponin, for the early detection of the potential heart damage [39].

It is well known that cardiotoxicity occurs through various mechanisms, either directly or indirectly, addressed to the myocytes function. Among the principal chemiotherapy drugs potentially dangerous for the heart, antracicline, taxani and oxalipatin are the most commonly used. Two principal mechanisms are recognized in the myocardial damage in the case of chemotherapy: firstly, a first mechanism "dose dependence and irreversibility" well evidenced in cytostatic drugs and also in antracicline; secondly, "no dose cumulative dependence" and potentially reversible dependence, as in the case of receptors inhibitors. In the first case the pathogenesis is related to the oxidative stress, which induces a free radical production; in the second, the damage is a consequence of specific cell dysfunction due to a blockage of a specific metabolic cell paths. The damage can therefore be either dose-dependent, as in case of anthracycline, or not, as in the case of ant HERB2 (trastuzumab) regimen. Some other specific cytoxic chemiotherapic drugs, such as 5-Fluoruracyl, oxaliplatin, etc., can be associated with a myocardial ischemia [41]. This aspect highlights the importance to perform a continuous non-invasive investigation, especially when there is a combination of the chemiotherapics as in case of taxani and antraciclines where the association can enhance the damage.

A critical aspect is that cardiotoxicity can also occur after 20-25 years from the beginning of the pharmacological chemotherapy treatment [39] and some strategies have been considered to reduce cardiotoxicity, especially the anthracycline-induced cardiotoxicity. This aspect has been largely studied in the pediatric population, both in human and in animal models [41,42]. The LV EF alone has been recognized to be not significant enough for the early detection of most potential damage of the heart's function. In the case of cancer patients, it has low sensitivity for the detection of small changes in LV function.

The EF, calculated by conventional 2D echocardiography, often fails to detect small changes in LV contractility because of several factors. These include the different LV geometric assumptions, inadequate visualization of the true LV apex, lack of consideration of subtle regional wall motion abnormalities, and inherent variability of the measurement [43].

It is also important to bear in mind the load dependency of this measurement. Changes in loading conditions are frequent during chemotherapy and they may affect the EF value, for example, volume expansion due to the intravenous administration of chemotherapy or volume contraction due to vomiting or diarrhea. Volumetric reduction can remain approximately normal for a long time, especially if the patients are not yet symptomatic; however, the literature reports that, often, deformation parameters are capable to detect the myocardial dysfunction with preserved EF early, especially in case oncological patients [44,45]. In our clinical experience, athletes previously affected 
by cancer can also take great advantage in echocardiographic strain analysis, during the sport's activity follow-up [46].

The population of oncological athletes, in addition to the cancer patients, keeps growing, although different clinical implications and diverse impact of the physical activity are practiced. Despite these differences, GLS is currently considered the best and most direct parameter to manage the amount and the intensity of the physical activity.

In this particular category of athletes, the amount of daily or weekly physical activity is very important to guarantee the benefits in terms of cardiovascular performance, but also in terms of anti-inflammatory process. For this reason an assessment of the role of GLS in different doses of moderate aerobic exercise, compared to sports activity has been investigated in previous breast cancer survivors [46].

In view of the importance of a complete lifestyle intervention in cancer patients, and also considering that multiple professional approaches are needed, especially when physical activity is allowed, the cardioncology approach seems to be an investigation that is not optional. When cardiotoxicity is suspected, deformation parameters are very helpful and now considered capable to detect the developing heart failure early [47]. A specific echo evaluation plays an important role in this phase of the cancer disease.

Considering that cancer patients live longer, their risk of developing secondary cardiovascular events increases.

Strain, and particularly GLS measurements, appeared therefore to be a sensitive indicators for sub-clinical diseases, including diabetes [48], myocardial ischemia [49] arterial hypertension [50] and non-ischemic cardiomyopathies. Multiple actual clinical applications can be proposed in the case of coexistence of many NCCD like in the case of metabolic syndrome.

An interesting study has also been conducted in adolescents, for whom obesity is considered a strong risk factor for premature atherosclerotic cardiovascular disease [51]. The rapid development of novel cancer therapies will continue to generate questions of cardiac risk and cardiac protection in cancer patients over time. Cancer survival has been greatly impacted upon by the development of modern cancer treatments and cardio-oncology is a field in rapid evolution [52]. Recent echocardiographic noninvasive techniques are expected to provide large clinical implications in acute and chronic cancer patients. In this context, deformation parameters, mainly GLS, are increasingly being used, and the first clinical approach to patients is starting.

\section{Conclusions}

Cancer patients who are free of disease, or even in presence of a periodical recurrence of the disease, are encouraged to restart with a normal lifestyle in which physical activity is allowed. In this case, cardiologic follow-up is mandatory.

Echocardiography is a noninvasive, non-radiating imaging method to assess and follow up patients with cancer. This is one of the principal advantages of this method. Particularly, deformation parameters like Strain and Strain Rate are very largely used in the clinical approach of the cancer patients during acute or chronic disease, with a high reproducibility of the results. Considering the positive impact of the regular physical training in cancer survivors $[3,46,53]$, a new category of potential athletes, previously affected by cancer or with intermittent NCCD, is inevitably emerging. The management of the balance between the physical activity and the sports activity can be difficult in the absence of the real visualization of preserved cardiovascular function. The role of the strain analysis in acute and chronic cancer patients needs to be highlighted to improve primary and secondary prevention of cardiomyopathies. In our experience, and as the literature reports, particularly GLS can be proposed to confirm or to exclude the presence of any potential myocardial damage and therefore to allow or contraindicate physical activity or sports, despite a previous history of cardiotoxicity. This aspect is principally important in the case of subjects who are completely asymptomatic or with a history of a transient heart failure, and where the regular and continuous 
follow-up is fundamental. The present brief review on this new aspect of the non-Invasive cardiology in the oncological world, cannot be considered a systematic review and some limits can be identified, especially in the methological approach. It can be considered as a glance on the recent literature that has been updated and opportunely selected for this aim and to answer to the principal query of the manuscript. Despite non-specific statistical guidelines having been applied, the simple interrogations of the principal research focus seen in the Internet have answered our questions.

Acknowledgments: we like to thank Stefano Pedri (Esaote) for his continue support to the clinical application of the XStrain software in our work and for giving us the possibility to take place to his experience.

Author Contributions: All authors jointly conceived the manuscript. Laura Stefani performed clinical analysis and drafted the manuscript, Gianni Pedrizzetti supervised the technical part of analysis and revised the manuscript, Giorgio Galanti supervised the clinical part of analysis and revised the manuscript. All authors have approved the final version. No funding has been received for this investigation.

Conflicts of Interest: The authors declare no conflict of interest.

\section{References}

1. Sheehan, F.H. Quantitative evaluation of regional left ventricular systolic function. In The Practice of Clinical Echocardiography; Otto, C.M., Ed.; WB Saunders Company: Philadelphia, PA, USA, 2002; pp. 65-87.

2. Claus, P.; Omar, A.M.; Pedrizzetti, G.; Sengupta, P.P.; Nagel, E. Tissue tracking technology for assessing cardiac mechanics: Principles, normal values, and clinical applications. JACC Imaging 2015, 8, 1444-1460. [CrossRef] [PubMed]

3. Stefani, L.; Petri, C.; Mascherini, G.; Galanti, G. Lifestyle intervention in survivors cancer patients. J. Funct. Morphol. Kinesiol. 2016, 1, 48-53. [CrossRef]

4. Yu, A.F.; Raikhelkar, J.; Zabor, E.C.; Tonorezos, E.S.; Moskowitz, C.S.; Adsuar, R.; Mara, E.; Huie, K.; Oeffinger, K.C.; Steingart, R.M.; et al. Two-dimensional speckle tracking echocardiography detects subclinical left ventricular systolic dysfunction among adult survivors of childhood, adolescent, and young adult. Cancer Biomed. Res. Int. 2016, 2016, 9363951. [CrossRef] [PubMed]

5. Seidman, A.; Hudis, C.; Pierri, M.K.; Shak, S.; Paton, V.; Ashby, M.; Murphy, M.; Stewart, S.J.; Keefe, D. Cardiac dysfunction in the trastuzumab clinical trials experience. J. Clin. Oncol. 2002, 20, 1215-1221. [CrossRef] [PubMed]

6. Bowles, E.J; Wellman, R.; Feigelson, H.S.; Onitilo, A.A.; Freedman, A.N.; Delate, T.; Allen, L.A.; Nekhlyudov, L.; Goddard, K.A.; Davis, R.L.; et al. Risk of heart failure in breast cancer patients after anthracycline and trastuzumab treatment: A retrospective cohort study. J. Natl. Cancer Inst. 2012, 104, 1293-1305. [CrossRef] [PubMed]

7. Cuzick, J.; Stewart, H.; Rutqvist, L.; Houghton, J.; Edwards, R.; Redmond, C. Cause-specific mortality in long-term survivors of breast cancer who participated in trials of radiotherapy. J. Clin. Oncol. 1994, 12, 447-453. [PubMed]

8. Ewer, M.S.; Ali, M.K.; Mackay, B.; Wallace, S.; Valdivieso, M.; Legha, S.S.; Benjamin, R.S.; Haynie, T.P. A comparison of cardiac biopsy grades and ejection fraction estimations in patients receiving Adriamycin. J. Clin. Oncol. 1984, 2, 112-117. [PubMed]

9. Aurigemma, G.P.; Douglas, P.S.; Gaasch, H.W. Quantitative evaluation of left ventricular structure, wall stress and systolic function. In The Practice of Clinical Echocardiography; Otto, C.M., Ed.; WB Saunders Company: Philadelphia, PA, USA, 2002; pp. 65-87.

10. Lancellotti, P.; Anker, S.D.; Donal, E.; Edvardsen, T.; Popescu, B.A.; Farmakis, D.; Filippatos, G.; Habib, G.; Maggioni, A.P.; Jerusalem, G.; et al. EACVI/HFA cardiac oncology toxicity registry in breast cancer patients: Rationale, study design, and methodology (EACVI/HFA COT Registry)-EURObservational Research Program of the European Society of Cardiology. Eur. Heart J. Cardiovasc. Imaging 2015, 16, 466-470. [CrossRef] [PubMed]

11. Stouylen, A.; Heimdal, A.; Bjornstad, K.; Torp, H.G.; Skjaerpe, T. Strain rate imaging by ultrasound in the diagnosis of regional dysfunction of the left ventricle. Echocardiography 1999, 16, 321-329. [CrossRef]

12. Negishi, K.; Negishi, T.; Kurosawa, K.; Hristova, K.; Popescu, B.A.; Vinereanu, D.; Yuda, S.; Marwick, T.H. Practical Guidance in Echocardiographic Assessment of Global Longitudinal Strain. JACC Cardiovasc. Imaging 2015, 4, 489-492. [CrossRef] [PubMed] 
13. Heimdal, A.; Stoylen, A.; Torp, H.; Skjaerpe, T. Real time strain rate imaging of the left verntricle by ultrasound. J. Am. Soc. Echocardiogr. 1998, 11, 1013-1019. [CrossRef]

14. Malpica, N.; Santos, A.; Zuluaga, M.A.; Ledesma, M.J.; Pérez, E.; García-Fernández, M.A.; Desco, M. Tracking of regions-of-interest in myocardial contrast echocardiography. Ultrasound Med. Biol. 2004, 30, 303-309. [CrossRef] [PubMed]

15. Leitman, M.; Lysyansky, P.; Sidenko, S.; Shir, V.; Peleg, E.; Binenbaum, M.; Kaluski, E.; Krakover, R.; Vered, Z. Two-dimensional strain-A novel software for real-time quantitative echocardiographic assessment of myocardial function. J. Am. Soc. Echocardiogr. 2004, 17, 1021-1029. [CrossRef] [PubMed]

16. Vannan, M.A.; Pedrizzetti, G.; Li, P.; Gurudevan, S.; Houle, H.; Main, J.; Jackson, J.; Nanda, N.C. Effect of cardiac resynchronization therapy on longitudinal and circumferential left ventricular mechanics by velocity vector imaging: Description and initial clinical application of a novel method using high-frame rate B-mode echocardiographic images. Echocardiography 2005, 22, 826-830. [CrossRef] [PubMed]

17. Shiino, K.; Yamada, A.; Ischenko, M.; Khandheria, B.K.; Hudaverdi, M.; Speranza, V.; Harten, M.; Benjamin, A.; Hamilton-Craig, C.R.; Platts, D.G.; et al. Intervendor consistency and reproducibility of left ventricular 2D global and regional strain with two different high-end ultrasound systems. J. Eur. Heart J. Cardiovasc. Imaging 2016. [CrossRef] [PubMed]

18. Tadic, M.; Cuspidi, C.; Vukomanovic, V.; Celic, V.; Tasic, I.; Stevanovic, A.; Kocijancic, V.J. Does masked hypertension impact left ventricular deformation? Am. Soc. Hypertens. 2016. [CrossRef] [PubMed]

19. Kafa, R.; Kusunose, K.; Goodman, A.L.; Svensson, L.G.; Sabik, J.F.; Griffin, B.P.; Desai, M.Y. Association of abnormal postoperative left ventricular global longitudinal strain with outcomes in severe aortic stenosis following aortic valve replacement. JAMA Cardiol. 2016, 1, 494-496. [CrossRef] [PubMed]

20. Stefani, L.; Pedrizzetti, G.; Pedri, S.; Minetti, E.; Mandoli, M.; Tosi, B.; Galanti, G. Cardiovascular outcomes in renal transplant 2 recipients: Feasibility and clinical role of 2D speckle 3 tracking to assess myocardial function. J. Funct. Morphol. Kinesiol. 2016, 1, 109-117. [CrossRef]

21. Bae, H.K.; Choi, H.S.; Sohn, S.; Shin, H.J.; Nam, J.H.; Hong, Y.M. Cardiovascular screening in asymptomatic adolescents with metabolic syndrome. J. Cardiovasc. Ultrasound 2015, 23, 10-19. [CrossRef] [PubMed]

22. Kosmala, W.; Przewlocka-Kosmala, M.; Sharman, J.E.; Schultz, M.G.; Marwick, T.H. Stability of left ventricular longitudinal and circumferential deformation over time and standard loading conditions. Eur. Heart J. Cardiovasc. Imaging 2016. [CrossRef] [PubMed]

23. D'Amore, C.; Gargiulo, P.; Paolillo, S.; Pellegrino, A.M.; Formisano, T.; Mariniello, A.; Della Ratta, G.; Iardino, E.; D'Amato, M.; La Mura, L.; et al. Nuclear imaging in detection and monitoring of cardiotoxicity. World J. Radiol. 2014, 6, 486-492. [CrossRef] [PubMed]

24. Wassmuth, R.; Lentzsch, S.; Erdbruegger, U.; Schulz-Menger, J.; Doerken, B.; Dietz, R.; Friedrich, M.G. Subclinical cardiotoxic effects of anthracyclines as assessed by magnetic resonance imaging-A pilot study. Am. Heart J. 2001, 141, 1007-1013. [CrossRef] [PubMed]

25. Saito, K.; Takeda, K.; Okamoto, S.; Okamoto, R.; Makino, K.; Tameda, Y.; Nomura, Y.; Maeda, H.; Ichihara, T.; Nakano, T. Detection of doxorubicin cardiotoxicity by using iodine-123 BMIPP early dynamic SPECT: Quantitative evaluation of early abnormality of fatty acid metabolism with the Rutland method. J. Nucl. Cardiol. 2000, 7, 553-5612. [CrossRef] [PubMed]

26. Nony, P.; Guastalla, J.P.; Rebattu, P.; Landais, P.; Lievre, M.; Bontemps, L.; Itti, R.; Beaune, J.; Andre-Fouet, X.; Janier, M. In vivo measurement of myocardial oxidative metabolism and blood flow does not show changes in cancer patients undergoing doxorubicin therapy. Cancer Chemother. Pharmacol. 2000, 45, 375-380. [CrossRef] [PubMed]

27. Jeong, E.M.; Dudley, S.C. Diastolic dysfunction: Potential new diagnostics and therapies. Circ. J. 2015, 79, 470-477. [CrossRef] [PubMed]

28. Daneshvar, D.; Wei, J.; Tolstrup, K.; Thomson, L.E.; Shufelt, C.; Merz, C.N. Diastolic dysfunction: Improved understanding using emerging imaging techniques. Am. Heart J. 2010, 160, 394-404. [CrossRef] [PubMed]

29. Nair, N.; Gongora, E. Heart failure in chemotherapy-related cardiomyopathy: Can exercise make a difference? BBA Clin. 2016, 6, 69-75. [CrossRef] [PubMed]

30. Voigt, J.U.; Pedrizzetti, G.; Lysyansky, P.; Marwick, T.M.; Houle, H.; Baumann, R.; Pedri, S.; Ito, Y.; Abe, Y.; Metz, S.; et al. Definitions for a common standard for 2D Speckle tracking echocardiography: Consensus document of the EACVI/ASE/industry task force to standardize deformation imaging. Eur. Heart J. Cardiovasc. Imaging 2015, 16, 1-11. [CrossRef] [PubMed] 
31. Stanton, T.; Leano, R.; Marwick, T.H. Prediction of all-cause mortality from global longitudinal speckle strain: Comparison with ejection fraction and wall motion scoring. Circ. Cardiovasc. Imaging 2009, 2, 356-364. [CrossRef] [PubMed]

32. Pedrizzetti, G.; Mangual, J.; Tonti, G. On the relationship between global longitudinal strain and ejection fraction. J. Biomech. 2014, 47, 746-749. [CrossRef] [PubMed]

33. Nagueh, S.F.; Smiseth, O.A.; Appleton, C.P.; Byrd, B.F.; Dokainish, H.; Edvardsen, T.; Flachskampf, F.A.; Gillebert, T.C.; Klein, A.L.; Lancellotti, P.; et al. Recommendations for the evaluation of left ventricular diastolic function by echocardiography: An update from the American Society of Echocardiography and the European Association of Cardiovascular Imaging. J. Am. Soc. Echocardiogr. 2016, 29, 277-314. [CrossRef] [PubMed]

34. Mor-Avi, V.; Lang, R.M.; Badano, L.P.; Belohlavek, M.; Cardim, N.M.; Derumeaux, G.; Galderisi, M.; Marwick, T.; Nagueh, S.F.; Sengupta, P.P.; et al. Current and evolving echocardiographic techniques for the quantitative evaluation of cardiacmechanics: ASE/EAE consensus statement on methodology and indications. Eur. J. Echocardiogr. 2011, 12, 167-205. [CrossRef] [PubMed]

35. Yu, C.M.; Sanderson, J.E.; Marwick, T.H.; Oh, J.K. Tissue Doppler imaging a new prognosticator for cardiovascular diseases. J. Am. Coll. Cardiol. 2007, 20, 234-243.

36. Marciniak, A.; Sutherland, G.R.; Marciniak, M.; Claus, P.; Bijnens, B.; Jahangiri, M. Myocardial deformation abnormalities in patients with aortic regurgitation: A strain rate imaging study. Eur. J. Echocardiogr. 2009, 10, 112-119. [CrossRef] [PubMed]

37. Fei, H.W.; Ali, M.T.; Tan, T.C.; Cheng, K.H.; Salama, L.; Hua, L.; Zeng, X.; Halpern, E.F.; Taghian, A.; MacDonald, S.M.; et al. Left ventricular global longitudinal strain in HER-2 + breast cancer patients treated with anthracyclines and trastuzumab who develop cardiotoxicity is associated with subsequent recovery of left ventricular ejection fraction. Echocardiography 2016, 33, 519-526. [CrossRef] [PubMed]

38. Stefani, L.; Galanti, G.; Pedri, S.; Tosi, B.; Pedrizzetti, G. Evaluation of myocardial function in female athletes post breast cancer. Med. Sci. Sports Exerc. 2016, 48 (Suppl. 1), 187-188. [CrossRef] [PubMed]

39. Chung, W.B.; Youn, H.J. Pathophysiology and preventive strategies of anthracycline-induced cardiotoxicity. Korean J. Intern. Med. 2016, 31, 625-633. [CrossRef] [PubMed]

40. Potier, A.; Ederhy, S.; Ancedy, Y.; Etienney, A.; Soulat-Dufour, L.; Chauvet, M.; Hollebecque, A.; Adavane-Scheuble, S.; Boccara, F.; Soria, J.C.; et al. Early detection of cancer therapeutics-related cardiac dysfunction. Bull. Cancer 2016. [CrossRef]

41. Ryerson, A.B.; Border, W.L.; Wasilewski-Masker, K.; Goodman, M.; Meacham, L.; Austin, H.; Mertens, A.C. Assessing anthracycline-treated childhood cancer survivors with advanced stress echocardiography. Pediatr. Blood Cancer 2015, 62, 502-508. [CrossRef] [PubMed]

42. Gziri, M.M.; Pokreisz, P.; de Vos, R.; Verbeken, E.; Debiève, F.; Mertens, L.; Janssens, S.P.; Amant, F. Fetal rat hearts do not display acute cardiotoxicity in response to maternal Doxorubicintreatment. J. Pharmacol. Exp. Ther. 2013, 346, 362-369. [CrossRef] [PubMed]

43. Jacobs, L.D.; Salgo, I.S.; Goonewardena, S.; Weinert, L.; Coon, P.; Bardo, D.; Weinert, L.; Gerard, O.; Allain, P.; Zamorano, J.L.; et al. Rapid online quantification of left ventricular volume from real-time three-dimensional echocardiographic data. Eur. Heart J. 2006, 27, 460-468. [CrossRef] [PubMed]

44. Otterstad, J.E.; Froeland, G.; St John, S.M.; Holme, I. Accuracy and reproducibility of biplane two-dimensional echocardiographic measurements of left ventricular dimensions and function. Eur. Heart J. 1997, 18, 507-513. [CrossRef] [PubMed]

45. Thavendiranathan, P.; Poulin, F.; Lim, K.D.; Plana, J.C.; Woo, A.; Marwick, T.H. Use of myocardial strain imaging by echocardiography for the early detection of cardiotoxicity in patients during and after cancer chemotherapy: A systematic review. J. Am. Coll. Cardiol. 2014, 63, 2751-2768. [CrossRef] [PubMed]

46. Stefani, L.; Pedrizzetti, G.; Pedri, S.; Tosi, B.; Galanti, G. 2D longitudinal LV speckle tracking strain pattern in breast cancer survivors: Sports activity vs. exercise as prescription model. J. Am. Soc. Echocardiogr. 2016, 29, in press.

47. Hampton, T. Cardio-oncology programs strive to balance cancer care with heart health. Circulation 2016, 134, 353-354. [CrossRef] [PubMed]

48. Galderisi, M.; de Simone, G.; Inneli, P.; Innelli, P.; Turco, A.; Turco, S.; Capaldo, B.; Riccardi, G.; de Divitiis, O. Impaired inotropic response to type 2 diabetes mellitus: A strain rate imaging study. Am. J. Hypertens. 2007, 20, 548-555. [CrossRef] [PubMed] 
49. Edvardsen, T.; Skulstad, H.; Aakhus, S.; Urheim, S.; Ihlen, H. Regional myocardial systolic function during acute myocardial ischemia assessed by strain Doppler echocardiography. J. Am. Coll. Cardiol. 2001, 37, 726-730. [CrossRef]

50. Hensel, K.O.; Jenke, A.; Leischik, R. Speckle-tracking and tissue-doppler stress echocardiography in arterial hypertension: A sensitive tool for detection of subclinical LV impairment. BioMed Res. Int. 2014. [CrossRef] [PubMed]

51. Vitarelli, A.; Martino, F.; Capotosto, L.; Martino, E.; Colantoni, C.; Ashurov, R.; Ricci, S.; Conde, Y.; Maramao, F.; Vitarelli, M.; et al. Early myocardial deformation changes in hypercholesterolemic and obese children and adolescents: A 2D and 3D speckle tracking echocardiography study. Medicine 2014, 93, e71. [CrossRef] [PubMed]

52. Petek, B.J.; Greenman, C.; Herrmann, J.; Ewer, M.S.; Jones, R.L. Cardio-oncology: An ongoing evolution. Future Oncol. 2015, 11, 2059-2066. [CrossRef] [PubMed]

53. Demark-Wahnefried, W.; Lee, W.J. Promoting a healthy lifestyle among cancer survivors. Hematol. Oncol. Clin. N. Am. 2008, 22, 319-342. [CrossRef] [PubMed]

(C) 2016 by the authors; licensee MDPI, Basel, Switzerland. This article is an open access article distributed under the terms and conditions of the Creative Commons Attribution (CC-BY) license (http:/ / creativecommons.org/licenses/by/4.0/). 